\title{
ALGORITHM FOR SELF-TUNING THE PID CONTROLLER
}

\author{
Irina Cojuhari*, ORCID ID: 0000-0003-2248-1338 \\ Technical University of Moldova, 168 Stefan cel Mare blvd., Chisinau, Republic of Moldova \\ ${ }^{*}$ Corresponding author: Irina Cojuhari, irina.cojuhari@ati.utm.md
}

Received: 10. 21. 2021

Accepted: 11. 17. 2021

\begin{abstract}
An algorithm for self-tuning the PID controller to the second order systems is proposed in this paper. The proposed self-tuning procedure was developed according to the maximum stability degree criterion, the criterion that permits to achieve the high stability degree, good performance and robustness of the system. According to the proposed algorithm, the controller can be tuned according to the parameters that characterize the process and they can be determinate from the experimental response of the open loop system. To demonstrate the efficiency of proposed procedure of self-tuning the PID controller, the computer simulation was performed and the obtained results were compared with Haeri's method, maximum stability degree method with iterations and parametrical optimization method. According to the developed algorithm, it was performed the control of the thermal regime in the oven.
\end{abstract}

Keywords: automatic control system, self-tuning algorithm, second order systems, performance of the control system, PID controller.

Rezumat. Algoritmul de auto-acordare a regulatorului PID la sistemele de ordinul doi este propus în această lucrare. Algoritmul propus de auto-acordare a fost dezvoltat în baza criteriului gradului maximal de stabilitate, criteriul care oferă sistemului înalt grad de stabilitate, performanțe și robustețea ridicată. În conformitate cu algoritmul propus, regulatorul PID se acordează în dependență de parametrii care caracterizează procesul și care pot fi determinați din răspunsul indicial al sistemului deschis. Pentru a demonstra eficacitatea algoritmului propus a fost făcută simulare pe calculator și rezultatele obținute au fost comparate cu metoda Haeri, metoda gradului maximal de stabilitate cu iterații și optimizarea parametrică. Totodată, în conformitate cu algoritmul propus a fost proiectat algoritmul de reglare PID, în cazul sistemului de control a temperaturii în cuptor.

Cuvinte cheie: sistem de reglare automat, algoritm de auto-acordare, sistemele de ordinul doi, performanțele sistemului automat, regulator PID.

\section{Introduction}

The PID control algorithm is the most used control algorithm applied to control the technological processes of heavy and light industries, due to its simplicity, easy implementation and maintenance $[1,2]$. The practice of the automation demonstrates that 
the PID controllers and its variation still remain poorly tuned in many industrial applications, due to inadequate choice of sampling period, nonlinear properties of control object or actuators, poor signal filtering, or wrong estimation of the mathematical model [3 - 5].

From these consideration for the last 40 years researchers have been focused on development the self-tuning algorithms, without the need the manual parameter tuning. The self-tuning algorithms significant improve the procedure of finding the tuning parameters of the controller, by the automatically adjustment the tuning parameters and maintaining the stability and robustness of the control system [6].

The most known algorithms, that are used for self-tuning are the methods such as Ziegler-Nichols and Cohen-Coon, due the fact that these methods don't require to be known the mathematical model of the control object. The Ziegler -Nichols method can be used for the case of closed-loop systems in online mode, that suppose the control object to be excited to generate the critical oscillation regime, and according to which can be obtained the parameters for calculation the tuning parameters. The advantage of this method is the easy implementation, but as disadvantage can be considered the ensuring of the low performance of the system [7].

The Cohen-Coon method is applied for the open loop systems, for the case then control object has the slowly time-varying behavior with a large dead time [1]. The CohenCoon tuning method is used in offline mode, that means that a step change can be applied to the input of the system and then the output is obtained, and based on it is calculated the time constant and the time delay, that are used for tuning the PID controller.

In response to these limitations, the relay auto-tuning methods were proposed by Åström and Hägglund [8], that are widely used due to applicability in slow or highly nonlinear systems and simple mechanism of identification and calibration. Other methods for self-tuning were proposed by Dormido and Morilla and Ho et al. [9 - 10] based on sensitivity and phase margin; by Liu and Daley and Tan et al. based on the performance criterion [11]. More recent developments methods integrate the relay characteristic methods with algorithms from artificial intelligence such as the neural networks, evolutional algorithms and fuzzy control, that permit to reduce the effect of perturbation signal or nonlinear behavior of the control object. However, these approaches increase the complexity of the self-tuning algorithm [9-13].

In this work, it is presented the algorithm for self-tuning the PID controller to the second order systems with oscillate and aperiodic step response. The PID controller is proposed to be tuned based on the analytical expressions that were obtained according to the maximum stability degree (MSD) criterion $[14,15]$ and these expressions depend on the control object parameters, which can be obtained from the experimental curve of the openloop system.

\section{Self-Tuning PID Algorithm}

A. Identification procedure for control object with oscillate step response

It is assumed, that the oscillate step response of the open loop system is given, Figure 1. The transient response presented in the Figure 1, can be approximated with the following transfer function $[1,8]$ :

$$
H_{F}(s)=\frac{k \omega_{n}^{2}}{s^{2}+2 \xi \omega_{n} s+\omega_{n}^{2}}=\frac{k}{a_{0} s^{2}+a_{1} s+a_{2}},
$$




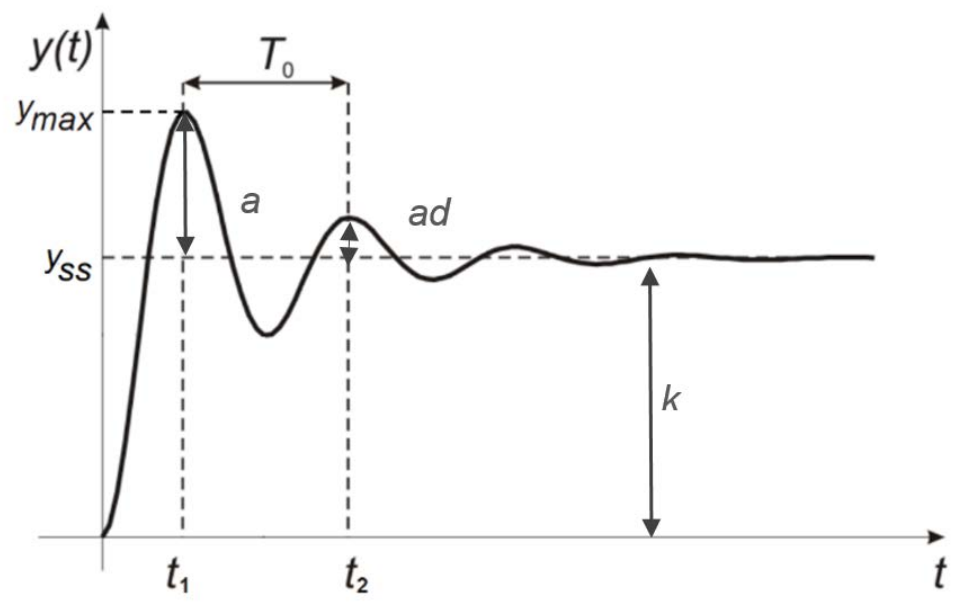

Figure 1. Oscillate step response.

where $\omega_{n}$ - natural frequency, $\xi$ - damping ratio, $k$ - transfer coefficient and $a_{0}=1 / \omega_{n}^{2}, a_{1}=$ $\frac{2 \zeta}{\omega_{n}}, a_{2}=1$.

The value of the damping ratio can be calculated from the experimental curve according to the following expression [8]:

$$
\xi=\frac{1}{\sqrt{1+(2 \pi / \log d)^{2}}}
$$

where $d$ - is decay ratio.

The value of the natural frequency can be calculated by:

$$
\omega_{n}=\frac{2 \pi}{T_{0} \sqrt{1-\zeta^{2}}}
$$

where $T_{0}=t_{2}-t_{1}$ is period of oscillation.

The value of the transfer coefficient can be calculated by the following relationship:

$$
k_{F}=\lim _{t \rightarrow \infty} \frac{\Delta y}{\Delta u}=\lim _{t \rightarrow \infty} \frac{y_{s t}-y_{\text {initial }}}{u-u_{\text {initial }}} .
$$

where $u$ - is the value of the input signal.

In this way the classical identification method of the second order transfer function is based on locating the value of overshoot and peaks at $t_{1}$ and $t_{2}$ [8].

B. Identification procedure for control object with aperiodic step response

It is assumed, that the aperiodic step response of the open loop system is given, Figure 2.

The transient response presented in the Figure 2 can be approximated with following transfer function [16]:

$$
H_{F}(s)=\frac{k}{\left(T_{1} s+1\right)\left(T_{2} s+1\right)}=\frac{k}{a_{0} s^{2}+a_{1} s+a_{2}},
$$

where $T_{1}, T_{2}$ - time constants, $k$ - transfer coefficient and $a_{0}=T_{1} T_{2}, a_{1}=T_{1}+T_{2}, a_{2}=1$. It is used the following procedure for determination the parameters $k, T_{1}, T_{2}$ : 
1. From the experimental curve (Figure 2), it is calculated the value of the transfer coefficient by the (4) relationship. Next it is calculate the value of the $y(t)$ at the level $0,632 k$, according to this value it is calculated the value of $t_{0}$ (Figure 2).

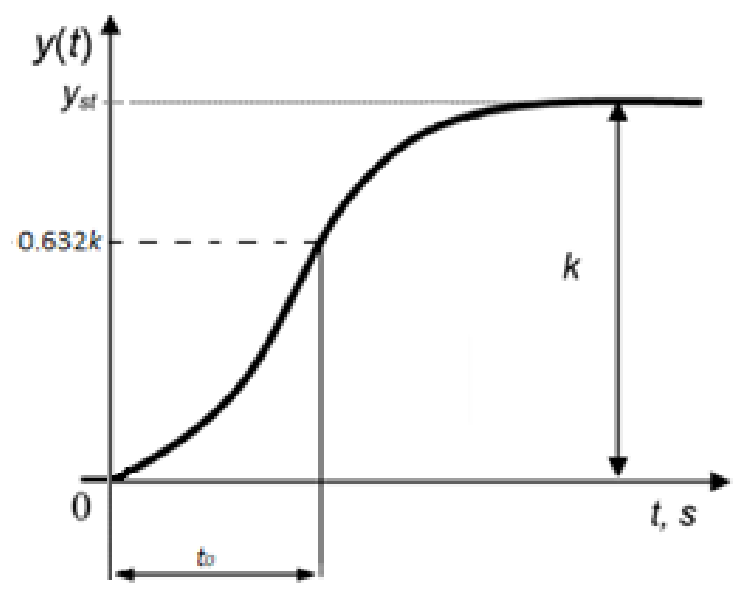

Figure 2. Aperiodic step response.

2. It is calculated the values of the time constants $T_{1}$ and $T_{2}$ for the model of object (5) [16 - 17]:

$$
\begin{gathered}
T_{1} / T_{2}=0.5, \\
T_{2}=0.64 t_{0}, \\
T_{1}=0.5 T_{2}=0.5 \cdot 0.64 t_{0}=0.32 t_{0} .
\end{gathered}
$$

By the relations (6), there are calculated the coefficients $a_{0}, a_{1}, a_{2}$ :

$$
\begin{gathered}
a_{0}=T_{1} T_{2}=0.32 \cdot 0.64 T^{2}=0.2048 T^{2}, \\
a_{1}=T_{1}+T_{2}=0.32 T+0.64 T=0.96 T, a_{2}=1 .
\end{gathered}
$$

C. Algorithm for self - tuning the PID controller

In this study, the automatic control system it is described by the structural scheme presented in the Figure 3, that consists from the controller with transfer function $H_{R}(s)$ and control object described by the (1) or (5) transfer functions.

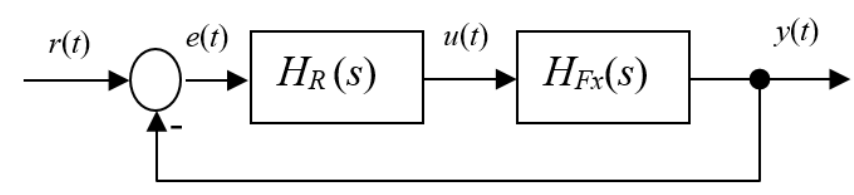

Figure 3. Structural scheme of the automatic control system.

The control algorithm PID is described by the following transfer function:

$$
H_{R}(s)=k_{p}+\frac{k_{i}}{s}+k_{d} s=\frac{k_{i}+k_{p} s+k_{d} s^{2}}{s},
$$


where the tuning parameters - $k_{p}, k_{i}, k_{d}$ are the coefficients for the proportional, integral, and derivative components of the PID controller.

One of the criterion, that is used for tuning the PID controller is the maximum stability degree criterion $[14,15,19]$. This criterion ensures the maximum displacement of the dominant poles of closed loop system to the imaginary axe in the left complex half plane (Figure 4).

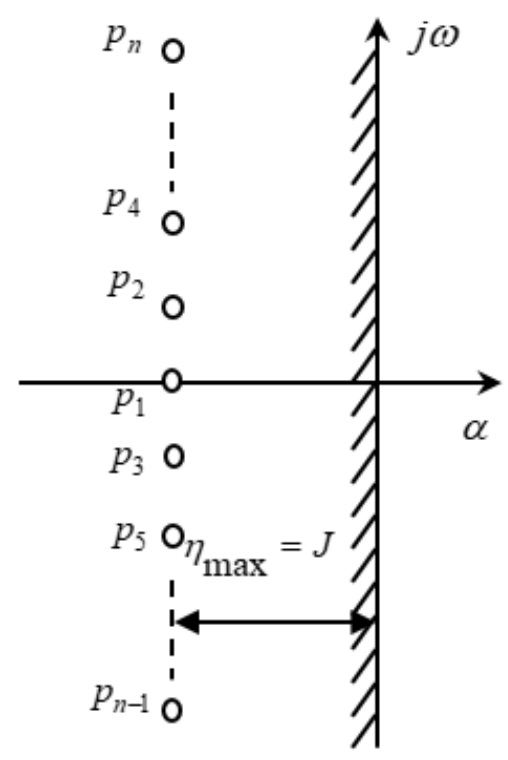

Figure 4. Placement of the poles in the left complex half plane for the system with MSD.

Based on the transfer functions in form (1) or (5) and transfer function of the PID controller (8), it was obtained the following characteristic equation of the closed loop control system

$$
A(s)=\frac{1}{k}\left(a_{0} s^{3}+a_{1} s^{2}+a_{2} s\right)+k_{d} s^{2}+k_{p} s+k_{i}
$$

According to the MSD criterion, the tuning parameters of the controller should be determinate, so as to be satisfied the condition [14 - 15]

$$
J=\eta_{m}=\max \eta\left(k_{p}, k_{i}, k_{d}\right),
$$

where $J$ is the maximum stability degree; $\eta$ - the stability degree of the system.

Statement 1. [18] If the coefficients $a_{0}$ and $a_{1}$ of the characteristic equation are set, than the stability degree $\eta$ of the stable system achieve the maximum possible value equal with

$$
J=\eta_{m}=\frac{a_{1}}{n a_{0}}
$$

when the real parts of all poles are equal to each other $\alpha_{1}=\alpha_{2}=\ldots=\alpha_{n}=J$.

In equation (10) $n$ is the degree of the characteristic equation of closed-loop control 
system. For the case when number of the tuning parameters is equal or less then the characteristic equation order, the value of the MSD can be chosen as arbitrary number [17]. Therefore, in this work, it was proposed that the MSD value to be calculated by the following expression:

$$
J=\eta_{m}=\frac{a_{1}}{(n-1) a_{0}}
$$

In the paper [19], it was developed MSD method with iteration for tuning the PID controllers and according to this method by the experimental way it was observed that

$$
J=\eta_{m}=\frac{k_{d}}{2 k_{p}} .
$$

In this case, by doing the equaling of the expressions (11) and (12), it is obtained

$$
\frac{k_{d}}{2 k_{p}}=\frac{a_{1}}{(n-1) a_{0}} \text {. }
$$

Next, according to the MSD method [15,19], there are obtained the analytical expressions for calculation the tuning parameters to the model of object (1) or (5):

$$
\begin{gathered}
k_{p}=\frac{1}{k}\left(-3 a_{0} J^{2}+2 a_{1} J-a_{2}\right)+2 k_{d} J, \\
k_{i}=\frac{1}{k}\left(a_{0} J^{3}-a_{1} J^{2}+a_{2} J\right)-k_{d} J^{2}+k_{p} J, \\
k_{d}=\frac{1}{2 k}\left(6 a_{0} J-2 a_{1}\right) .
\end{gathered}
$$

In this way, for the case of aperiodic transient response of the system, using the (12)(13) expressions, the functions (14)-(16) can be rewritten as:

$$
\begin{gathered}
k_{p}=\frac{a_{1}^{2}}{2 k a_{0}}=\frac{\left(T_{1}+T_{2}\right)^{2}}{2 k T_{1} T_{2}}, \\
k_{i}=\frac{a_{1}}{2 k a_{0}}=\frac{\left(T_{1}+T_{2}\right)}{2 k T_{1} T_{2}}, \\
k_{d}=\frac{a_{1}}{2 k}=\frac{T_{1}+T_{2}}{2 k} .
\end{gathered}
$$

For the case of oscillate transient response of the system, using the equations (2)-(3) the equations (17)-(19) can be rewritten as: 


$$
\begin{aligned}
& k_{p}=\frac{2 \xi^{2}}{k}, \\
& k_{i}=\frac{\xi \omega_{n}}{k}, \\
& k_{d}=\frac{\xi}{k \omega_{n}} .
\end{aligned}
$$

According to the expressions (17)-(19) and (20)-(22) the tuning parameters depend on the object parameters, that are known. In this way, the procedure of self-tuning can be implemented and requires the identification of the object parameters namely the damping ratio, transfer coefficient and natural frequency for the oscillate process, or time constants for aperiodic process, that can be determinate based on the experimental curve of the open loop system.

The algorithm for self-tuning the PID controller is following:

1. Obtaining the experimental curve of the open loop control system.

2. Identification the parameters of the model of object based on the experimental oscillate or aperiodic experimental curve, based on the expressions (2) and (3) and (4), or expressions (6)-(7).

3. Calculation the tuning parameters of the PID controller based on the expressions (17)-(19) for aperiodic process, or (20)-(22) for oscillate process.

\section{Study Case and Computer Simulation}

A. Tuning the PID controller to the control object with oscillate step response

It is considered, that the control object is described by the transfer function with inertia second order

$$
H_{F}(s)=\frac{k \omega_{n}^{2}}{s^{2}+2 \xi \omega_{n} s+\omega_{n}^{2}}=\frac{3}{s^{2}+s+3},
$$

where $\omega_{n}=1.73, \xi=0.288, k=1$.

Applying the expressions (20)-(22) there are obtained the values of the tuning parameters, that are presented in the Table 1 (row 1 ). The obtained results were compared with results obtained for the case of tuning the PID controller by the parametric optimization method (row 2), Haeri's method (row 3) [7], maximum stability degree method with iteration (row 4). The obtained simulation results are presented in the Figure 5, where the numbering of the curves correspond with the numbering of the methods from the Table 1.

Table 1

Tuning parameters and automatic system performance

\begin{tabular}{cccccccc}
\hline No. & $\boldsymbol{k}_{\boldsymbol{p}}$ & $\boldsymbol{k}_{\boldsymbol{i}}$ & $\boldsymbol{k}_{\boldsymbol{d}}$ & $\boldsymbol{t}_{\boldsymbol{s}}$ & $\boldsymbol{t}_{\boldsymbol{r}}$ & $\boldsymbol{\sigma}, \boldsymbol{\%}$ & $\boldsymbol{\eta}$ \\
\hline 1 & 0.16 & 0.49 & 0.16 & 4.40 & 7.8 & 0 & 0.5 \\
\hline 2 & 8.66 & 4.40 & 4.011 & 0.15 & 3.6 & 1.91 & 0.6 \\
\hline 3 & 8.38 & 0.11 & 0.929 & 0.23 & 132.7 & 21.91 & 0.01 \\
\hline 4 & 11.18 & 14.16 & 3.15 & 0.15 & 1.7 & 11.41 & 2.9 \\
\hline
\end{tabular}




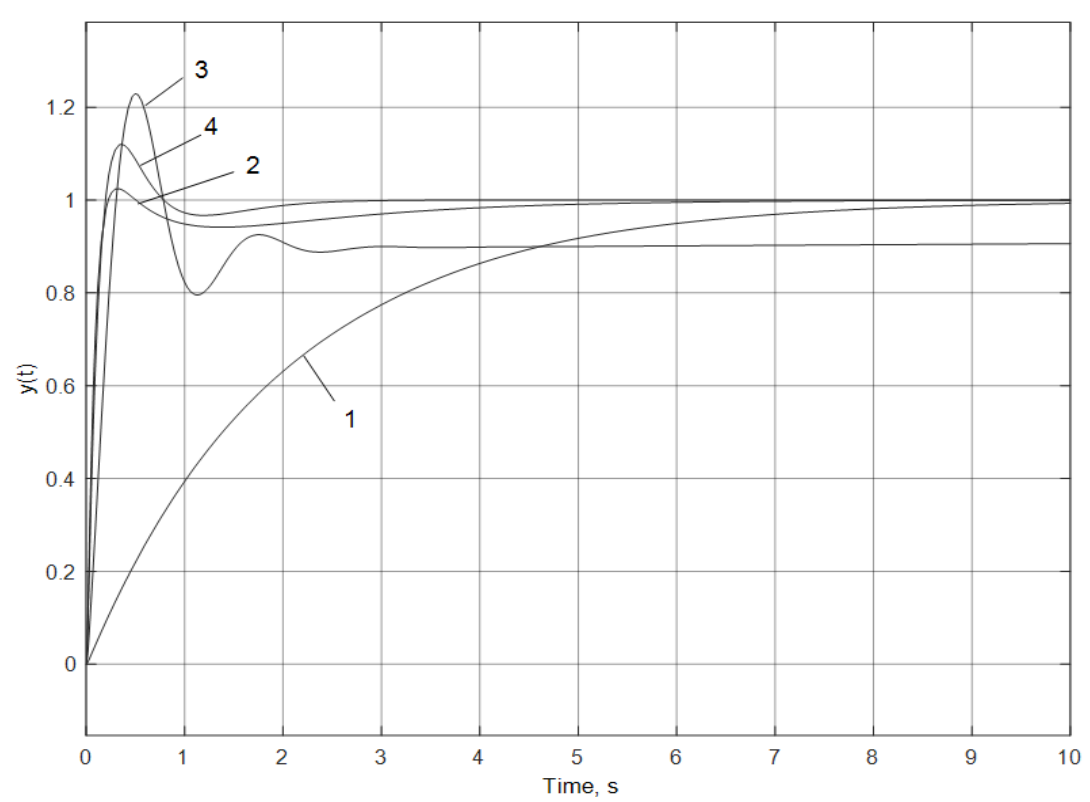

Figure 5. Transient response of the automatic control system.

From Figure 5, it can be observed, that in case of using the proposed algorithm for tuning the controller it can be obtained the aperiodic transient response without overshoot, with high settling time. The MSD criterion offers to the system the high stability degree and it was done the analysis of the systems' stability degree. There is obtained the distribution of poles and zeros of the closed loop system in the complex plan (Figure 6), where the numbering corresponds with the numbering of the methods from the Table 1 , and the obtained values of the stability degree for each method are presented in the Table 1.

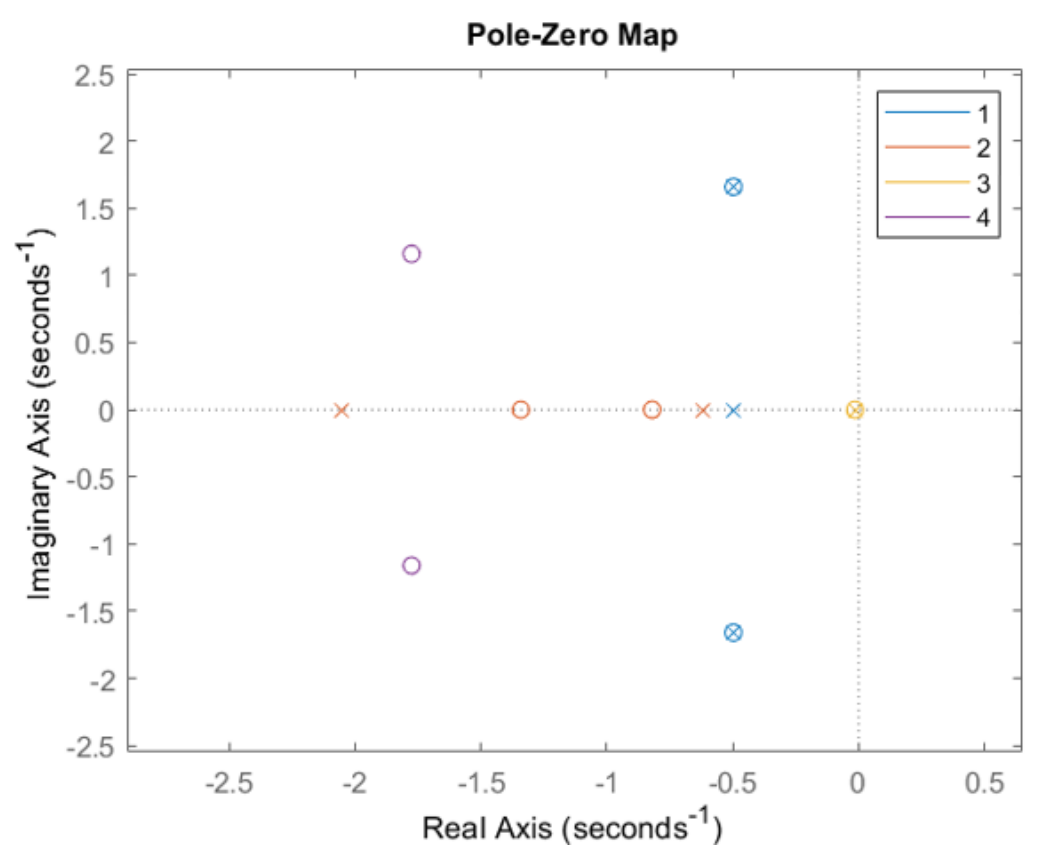

Figure 6. Poles-zeros distribution.

Next, it is presented an example of application the proposed algorithm of self-tuning the controller, it is supposed that control object is characterized by the oscillate transient response, Figure 7. According to the expressions (2)-(3) and (4) there are calculated $\omega_{n}$ $=0.1616, \xi=0.236, k=3$ and the transfer function that approximates the experimental curve

$$
\text { is: } H_{F}(s)=\frac{k \omega_{n}^{2}}{s^{2}+2 \xi \omega_{n} s+\omega_{n}^{2}}=\frac{0.0783}{s^{2}+0.0762 s+0.0261} \text {. }
$$




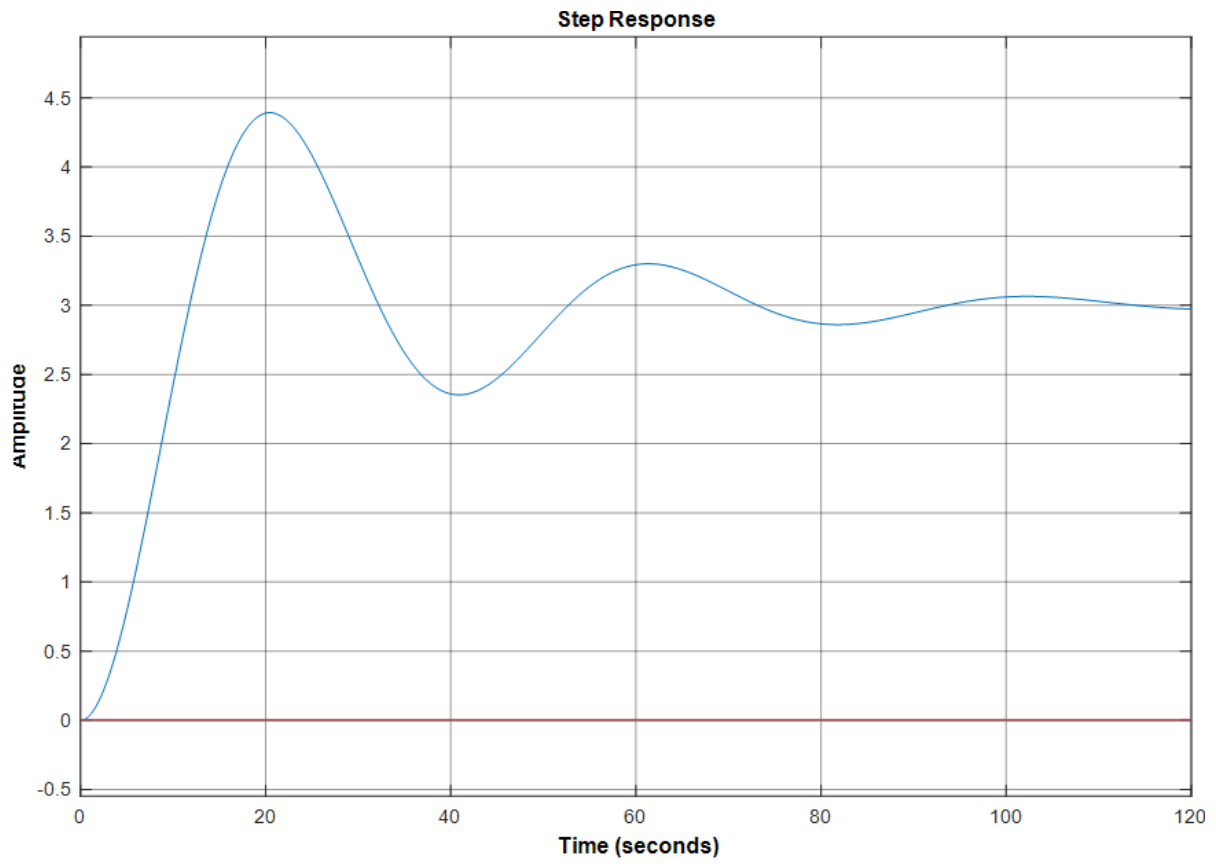

Figure 7. Step response.

Based on the expressions (20)-(22) for calculation the tuning parameters, there are obtained $k_{p}=0.037, k_{i}=0.012, k_{d}=0.488$ and the simulation result of control system is presented in the Figure 8.

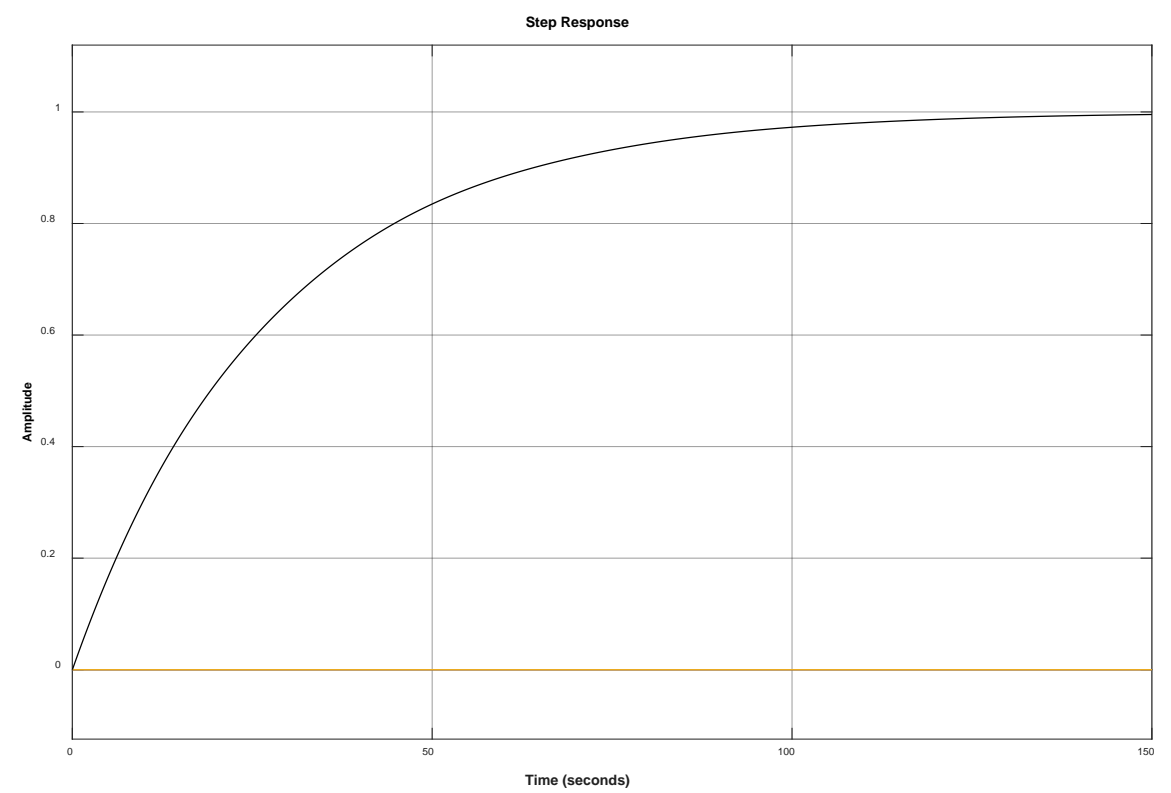

Figure 8. Transient response of the automatic control system.

B. Tuning the PID controller to the control object with aperiodic step response

It was proposed to control the thermal regime in the oven and to tune the PID controller according to the proposed algorithm. For the first step, it was necessary to determinate the mathematical model, that approximates the process of variation the temperature in the oven and it was raised the experimental curve (Figure 9).

Based on the described algorithm for approximation the aperiodic step response with transfer function (5), from the experimental curve (Figure 9) there are calculated that 0,632k is equal with 137.77 and according to this value there is obtained that $t_{0}=44.2696$, when the calculations are 


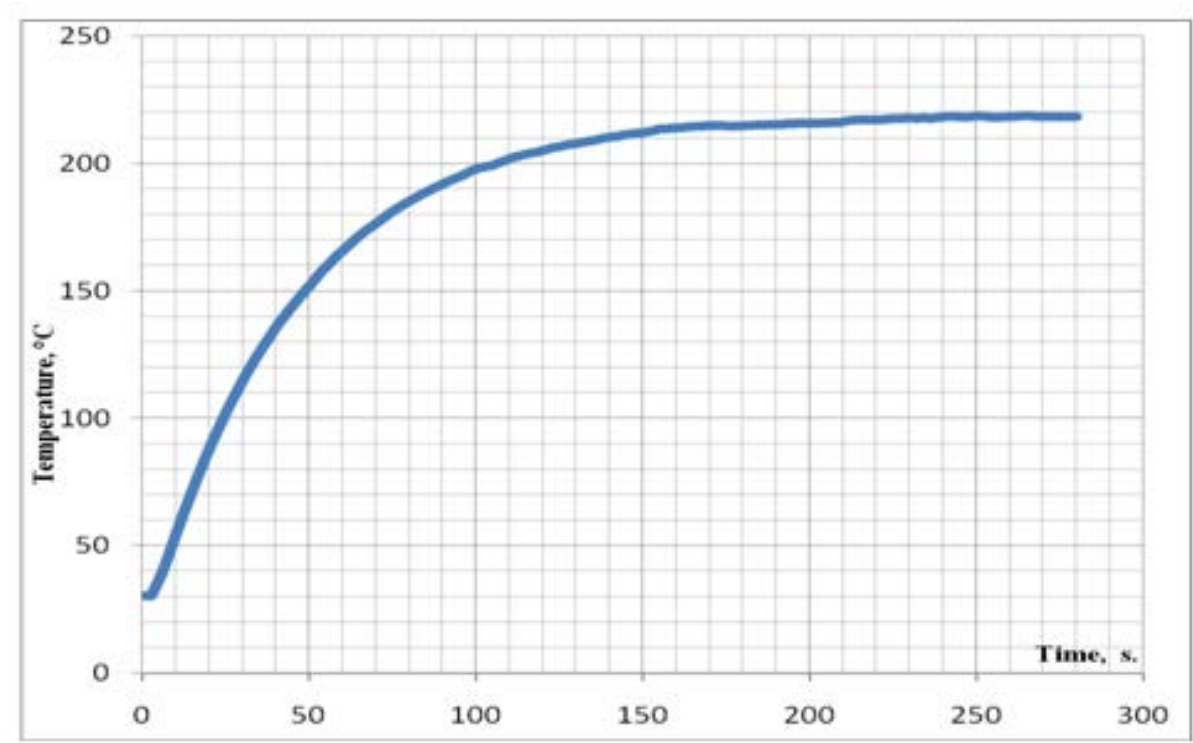

Figure 9. The experimental curve.

$$
T_{0}=0.64 \cdot 44.2696=28.3325 \mathrm{~s} . ; \quad T_{1}=0.5 \cdot 28.3325=14.1663 \mathrm{~s} .
$$

In this case the obtained transfer function is

$$
H_{F}(s)=\frac{k}{\left(T_{1} s+1\right)\left(T_{2} s+1\right)}=\frac{1.0035}{(28.3325 s+1)(14.1663 s+2)}=\frac{1.0035}{401.3667 s^{2}+42.4988 s+1} \text {. }
$$

Based on the expressions (17)-(19) for calculation the tuning parameters, there are obtained $k_{p}=2.2421, k_{i}=0.0528, k_{d}=21.175$ and the simulation results of control system with PID controller tuned by the proposed algorithm is presented in the Figure 10.

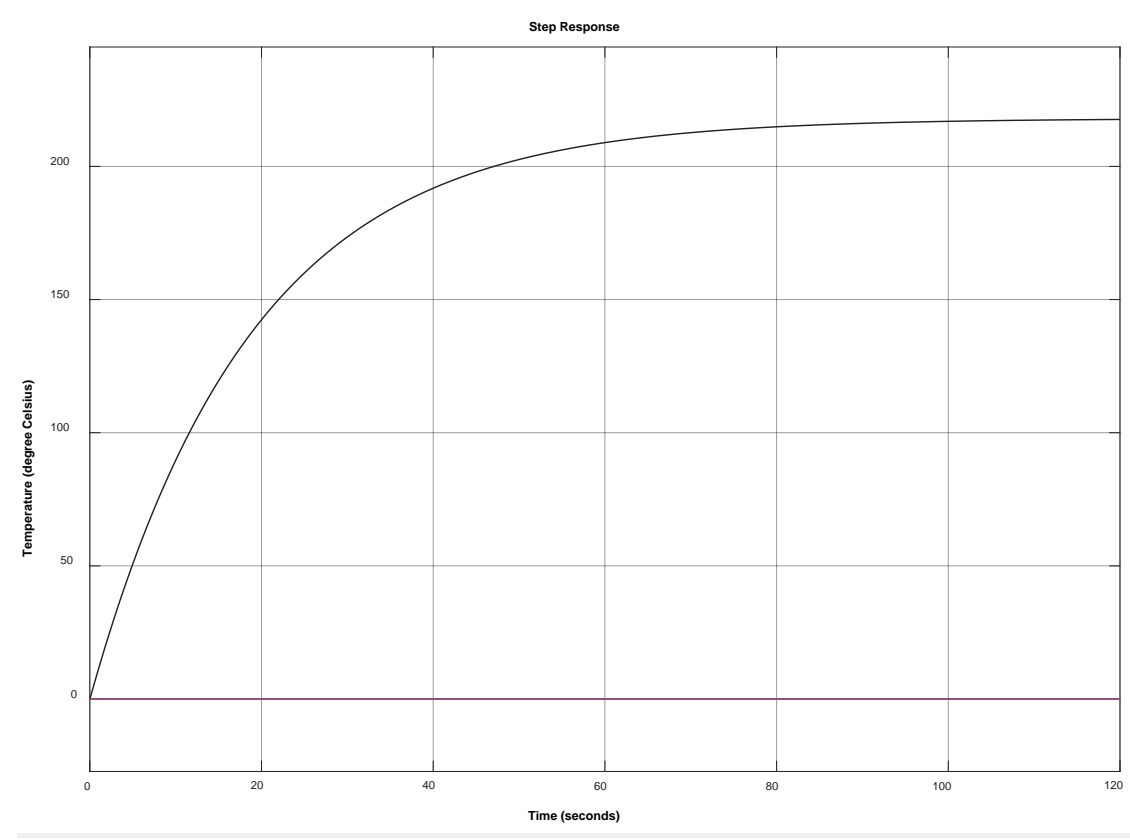

Figure 10. Transient response of the automatic control system.

\section{Conclusions}

An algorithm for self-tuning the PID controller to the second order systems is proposed in this paper. The tuning parameters can be calculated according to the proposed analytical expressions that depend on the value of the damping ratio, transfer coefficient and natural frequency of the system, which can be obtained from the experimental curve of the open- 
loop system. These expressions were developed according to the MSD criterion, the criterion that ensures the good performance and high stability degree to the system. To demonstrate the efficiency of the proposed algorithm it was done the computer simulation and the comparison with MSD method with iterations, the optimization method from MATLAB and Haeri's method. It was observed that the proposed self-tuning algorithm ensures to the system the aperiodic step response, but with high settling time.

\section{The paper was presented at the works of the conference ECCO 2021. Acknowledgments}

This work was supported by the project 20.80009.5007.26 „Models, algorithms and technologies for the control, optimization and security of the Cyber-Physical systems".

\section{References}

1. Dumitrache I. Ingineria reglarii automate. Bucureşti: Politehnica Press, 2005.

2. Bucz Š., Kozáková A. Advanced Methods of PID Controller Tuning for Specified Performance. In: PID Control for Industrial Processes, 2018, pp. 74-119.

3. Aldemir A., Anwer M. Determination of optimal PID control parameters by response surface methodology. In: International Advanced Researches and Engineering Journal, vol. 4, no. 2, 2020, pp. 142-153.

4. Borase R.P., Maghade D.K., Sondkar S.Y. et al., "A review of PID control, tuning methods and applications. In: Int. J. Dynam. Control 9, 2021, pp. 818-827.

5. Deliang Zeng, Zheng Yanqiu, Luo Wei, Hu Yong, Cui Qingru LI, Peng Qing. Chen Research on Improved AutoTuning of a PID Controller Based on Phase Angle Margin. In: Energies 12, No. 9, 2019, pp. 1-16.

6. O'dwyer A. Handbook of PI and PID controller tuning rules, 3rd Edition. Imperial College Press, 2009.

7. Ziegler J. G., Nichols N. B. Optimum settings for automatic controllers.USA:Research Triangle Park, 1992.

8. Astrom K. J., Hagglund T. PID Controllers, Theory, Design and Tuning. 2nd Edition, Instrument Society of America, 1995.

9. Dormido S., Morilla F. Tuning of PID controllers based on sensitivity margin specification. In: Proceedings of 5th Asian Control Conference, Melbourne, Australia, 1, 2004, pp. 486-491.

10. Ho W.K., Hong Y., Hansson A., Hjalmarsson H., Deng J.W. Relay auto-tuning of PID controllers using iterative feedback tuning. In: Automatica, Volume 39, Issue 1, 2003, pp. 149-157.

11. Hornsey S. A Review of Relay Auto-tuning Methods for the Tuning of PID-type Controllers. In: An International Journal of Undergraduate Research, 2018, Vol. 11 Issue 1, pp. 1-1.1.

12. Shen Jing-Chung, Chiang Huann-Keng PID tuning rules for second order systems. In: Proceedings of 5th Asian Control Conference, Vol.1., 2004, pp. 472-477.

13. Granado E., Mata E., Revollar S., Colmenares W., Pérez O. Study about system identification for second order process: an open and closed loop improvement. In: Revista Ingeniería UC, Vol. 11, No 1, 2004, pp. 41-47.

14. Fiodorov I., Izvoreanu B., Cojuhari I. Synthesis of Robust PID Controller by the Maximum Stability Degree Criterion. In: Proceedings of 2015 20th International Conference on Control Systems and Computer Science-CSCS2015, București, UPB, România, vol. 1, 2015, pp. 57-64.

15. Schubladze A. M. Sposobi sinteza system upravlenia maksimalinoi stepeni ustoichivosti [Methods of synthesis of control systems with maximum stability degree]. In: Avtomatika i telemehanika, No.1,1980, pp. 28-37.

16. Izvoreanu B., Potlog M., Cojuhari I., Fiodorov I., Moraru D. Metodă de Identificare a Modelelor Obiectului de Reglare de Ordinul Unu şi Doi după Răspunsul Experimental al Procesului [The method of identification the model of object with first and second order inertia by the experimental response of the process]. In: Proceedings of the IX International Conference on Microelectronics and Computer Science (ICMCS-2017), October 19-21, Chişinău, 2017, pp. 206-209.

17. Lukas V.A. B. A. Teoria avtomaticheskogo upravlenia [Automatic control theory]. Moskva: Nedra, 1990.

18. Kim D. P. Teoria avtomaticheskogo upravlenia T. 1. Lineinie sistemy [Automatic control theory. T. 1. Linear systems]. Moskva: FIZMATLIT, 2003.

19. Izvoreanu B., Cojuhari I., Fiodorov I., Moraru D., Potlog M. The Method for Synthesis the PI and PID Algorithms to the Model of Object with Inertia Second Order. In: Proceedings of the 2019 International Conference on Electromechanical and Energy Systems (SIELMEN), 2019, pp. 1 - 4. 